\title{
Measles surveillance in Canada: 2015
}

\author{
Sherrard $\mathrm{L}^{1 *}$, Hiebert $\mathrm{J}^{2}$, Cunliffe $\mathrm{J}^{1}$, Mendoza $\mathrm{L}^{2}$, Cutler $\mathrm{J}^{1}$
}

\section{Abstract}

Background: Measles has been eliminated in Canada since 1998. Every year, the Public Health Agency of Canada presents epidemiologic evidence to the Pan American Health Organization (PAHO) to verify that measles elimination continues in Canada.

Objective: To describe measles activity in Canada for 2015 as updated evidence for continued measles elimination status.

Methods: Measles surveillance data were captured by the Canadian Measles and Rubella Surveillance System (CMRSS) and the Measles and Rubella Surveillance (MARS) pilot project and assessed for distribution by demographics and risk factors. Outbreak characteristics were summarized and genotypic and phylogenetic analyses were conducted and described. Surveillance data for 2015 were evaluated against PAHO's essential criteria for measles elimination status.

Results: In 2015, the incidence of measles in Canada was 5.5 cases per 1,000,000 population, with 196 cases across four provinces. The majority of cases $(87.2 \%, n=171)$ were not immunized and both age-specific incidence rates and case counts were highest among those aged 10 to 14 years $(29.5$ cases per $1,000,000$ population, $n=55)$. This was due in large part to a sizeable outbreak in a non-immunizing religious community. Overall, $10.7 \%(n=21)$ of cases were hospitalized. Genotype information was available for $100 \%$ of measles events (4/4 outbreaks and 6/6 sporadic cases). Canada met or partially met most of PAHO's criteria for verification of measles elimination.

Conclusion: Although importations and areas of low immunization coverage continue to challenge Canada's elimination status, surveillance data for 2015 provides strong evidence that measles elimination has been maintained.

\section{Affiliations}

${ }^{1}$ Centre for Immunization and Respiratory Infectious Diseases, Public Health Agency of Canada, Ottawa, ON

${ }^{2}$ National Microbiology Laboratory, Public Health Agency of Canada, Winnipeg, MB

*Correspondence: lindsey. sherrard@phac-aspc.gc.ca

Suggested citation: Sherrard L, Hiebert J, Cunliffe J, Mendoza L, Cutler J. Measles surveillance in Canada: 2015. Can Comm Dis Rep 2016;42:139-45. https://doi.org/10.14745/ccdr.v42i07a01

\section{Introduction}

Measles is one of the most infectious diseases known. Before vaccines against measles became widely available, the disease was a significant cause of death and disability worldwide, leading to an estimated 2.6 million deaths every year (1).

In Canada, measles has been a nationally notifiable disease since 1924, except between 1959 and 1968. Enhanced, case-based surveillance of measles is coordinated by the Centre for Immunization and Respiratory Infectious Diseases and the National Microbiology Laboratory (NML) at the Public Health Agency of Canada, through the Canadian Measles and Rubella surveillance system (CMRSS) and the Measles and Rubella Surveillance (MARS) pilot project. Enhanced surveillance of measles is necessary to provide sufficient evidence for measles elimination.

The elimination of measles is defined as the absence of endemic measles transmission in a defined geographic area for 12 months or more, in the presence of a well-performing surveillance system (2). The elimination of measles in Canada has been described as an important and attainable public health objective since at least 1980 (3). During the 1992 Consensus Conference on Measles, Canada set the goal of achieving measles elimination by 2005 (4). This was revised at the 1994 XXIV Pan American Sanitary Conference, where Canada and other member states agreed to eliminate measles in the Americas by 2000 (5). Following the implementation of a two-dose routine immunization program against measles, the last endemic case in Canada was reported in 1997 and measles elimination status was achieved one year later (6).

Despite this success, Canada's elimination status continues to be challenged by importations of measles from other countries, where the disease remains endemic. In order to verify measles elimination status on an ongoing basis, Canada submits surveillance data to the Pan American Health Organization (PAHO). The objective of this report is to provide an epidemiologic summary of measles activity reported in Canada for the 2015 epidemiologic year. 


\section{Methods}

Surveillance data: On a weekly basis, measles cases meeting the national case definition (7) were reported by provinces and territories to PHAC via CMRSS or MARS ( $n=10$ and 3, provinces and territories respectively), including zero-reporting. Non-nominal, non-identifying case data were extracted and submitted to $\mathrm{PAHO}$. Confirmed measles cases with rash onset during the 2015 epidemiologic year (January 4, 2015 to January 2, 2016) were included in this report.

Genotyping: All measles virus genotyping was performed at PHAC's NML. The World Health Organization (WHO) standardized genotyping: sequencing of 450 nucleotides of the nucleoprotein $(\mathrm{N})$ gene (the $\mathrm{N}-450$ ), with the addition of the full length haemagglutinin $(\mathrm{H})$ gene (8) was attempted on all reverse transcription-polymerase chain reaction (RT-PCR) confirmed measles cases. The clinical specimens (respiratory and/or urine) were referred to the NML by provincial laboratories and were RT-PCR-confirmed in the provincial laboratories or at the NML. Measles $\mathrm{N}-450$ and $\mathrm{H}$ gene sequences were aligned with $\mathrm{WHO}$ genotype reference sequences (9) and maximum parsimony phylogenetic trees were generated using MEGA6 software (10). Genotypes were assigned by maximum homology of the $\mathrm{N}-450$ sequences to the WHO genotype reference sequences (9). Sequences were also deposited in the WHO measles nucleotide surveillance database (MeaNS, http://www.who-measles.org) and compared to so called "named strains" as well as sequences deposited by other members of the global measles laboratory network $(9,11)$.

Data management and validation: Measles surveillance data were managed using Microsoft Access 2010. A data validation process was conducted in March 2016, with the four provinces that reported measles cases in 2015. This included querying for blank fields, identifying illogical field entries and confirming values with reporting jurisdictions.

Analysis: SAS Enterprise Guide 5.1 (12) was used to perform descriptive epidemiologic analyses, for categorical variables (counts, proportions) and continuous values (medians, ranges). Incidence rates were calculated using Statistics Canada July 1, 2015 population estimates. The distribution of measles cases by demographics (e.g., age, gender, location), risk characteristics (e.g., immunization status, hospitalization, source of exposure) and genotype were assessed. Outbreak characteristics were summarized and surveillance data were evaluated against the essential criteria for the maintenance of measles elimination status, as described by PAHO (13).

Immunization status was defined in accordance with the routine, publicly-funded immunization schedule (14). Cases that were age-ineligible for routine immunization (i.e., aged less than one year or born before 1970) were classified as up-to-date, regardless of reported status. Those born after 1970 and aged seven years or more were defined as up-to-date with two doses. For those aged one to six years, either one or two doses were defined as up-to-date, depending on the recommended schedule in the reporting jurisdiction.

This routine public health surveillance activity was exempt from research ethics board approval.

\section{Results}

\section{Overview}

In 2015, the incidence of measles in Canada was 5.5 cases per $1,000,000$ population, with a total of 196 reported cases. These data include one case of measles in an international traveller, who was not reflected in the denominator. All cases were either laboratory-confirmed $(29.1 \%, \mathrm{n}=57)$ or epidemiologically linked to a laboratory-confirmed case $(70.9 \%, n=139)$.

The majority of cases $(99.5 \%, n=195)$ were reported between epidemiologic weeks 1 and 20, ending January 10 and May 23, 2015, respectively. A maximum of 87 (44.4\%) cases were reported during a single week, occurring during an outbreak in Quebec (week 9, ending March 7) (Figure 1).

\section{Figure 1: Number of reported measles cases, by epidemiologic week of rash onset and reporting province or territory, Canada, 2015}

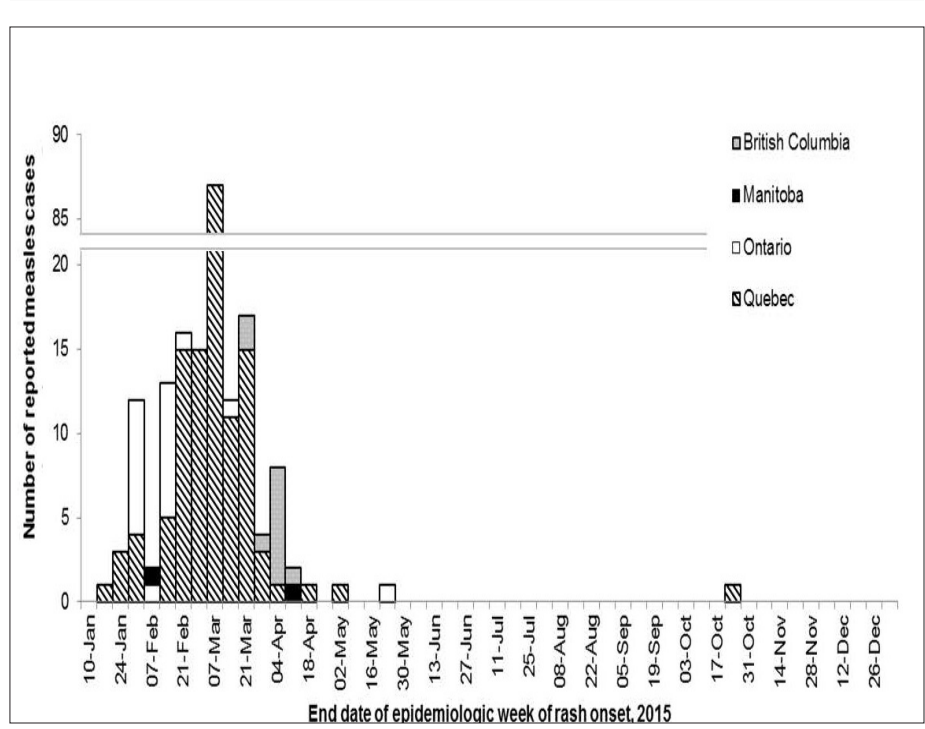

\section{Age, gender and location}

Information on age, gender and reporting province or territory was available for every case reported in 2015. Cases ranged in age from one month to 55 years, with a median age of 13.9 years. The most frequently reported age group was 10 to 14 years $(28.1 \%, n=55)$, followed by those aged 15 to 19 years $(19.9 \%, n=39)$ and five to nine years $(17.9 \%, n=35)$. Incidence rates were also highest for these groups, at 29.5, 18.6 and 17.9 cases per 1,000,000 population respectively (Table 1 ). There were no cases reported among those aged 60 years and older. Approximately half of the reported cases $(55.1 \%, n=108)$ were male. Four Canadian provinces reported measles cases in 2015: British Columbia, Manitoba, Ontario and Quebec. Incidence was highest in Quebec, followed by British Columbia, Manitoba and Ontario (19.7, 2.3, 1.5 and 1.5 cases per 1,000,000 population respectively). 
Table 3: Hospitalization status of confirmed measles cases by age group, Canada, 2015

\begin{tabular}{|c|c|c|c|c|c|c|c|}
\hline \multirow[b]{2}{*}{ Age group } & \multirow[b]{2}{*}{ Total } & \multicolumn{2}{|c|}{ Not hospitalized } & \multicolumn{2}{|c|}{ Hospitalized } & \multicolumn{2}{|c|}{ Unknown } \\
\hline & & $\mathrm{N}$ & $\%$ & $\mathrm{~N}$ & $\%$ & $\mathrm{~N}$ & $\%$ \\
\hline$<1$ year & 5 & 2 & $40.0 \%$ & 3 & $60.0 \%$ & 0 & $0.0 \%$ \\
\hline 1 to 4 years & 18 & 18 & $100.0 \%$ & 0 & $0.0 \%$ & 0 & $0.0 \%$ \\
\hline 5 to 9 years & 35 & 33 & $94.3 \%$ & 2 & $5.7 \%$ & 0 & $0.0 \%$ \\
\hline 10 to 14 years & 55 & 53 & $96.4 \%$ & 1 & $1.8 \%$ & 1 & $1.8 \%$ \\
\hline 15 to 19 years & 39 & 32 & $82.1 \%$ & 3 & $7.7 \%$ & 4 & $10.3 \%$ \\
\hline 20 to 24 years & 15 & 10 & $66.7 \%$ & 5 & $33.3 \%$ & 0 & $0.0 \%$ \\
\hline 25 to 29 years & 8 & 6 & $75.0 \%$ & 2 & $25.0 \%$ & 0 & $0.0 \%$ \\
\hline 30 to 39 years & 14 & 11 & $78.6 \%$ & 3 & $21.4 \%$ & 0 & $0.0 \%$ \\
\hline 40 to 59 years & 7 & 5 & $71.4 \%$ & 2 & $28.6 \%$ & 0 & $0.0 \%$ \\
\hline 60 years or more & 0 & 0 & - & 0 & - & 0 & - \\
\hline Total & 196 & 170 & $86.7 \%$ & 21 & $10.7 \%$ & 5 & $2.6 \%$ \\
\hline
\end{tabular}

Nearly all of the genotype B3 viruses identified were identical to the MVi/Harare.ZWE/38.09 (GenBank JF973033) named strain $(n=20)$ (Figure 3). All of these B3-Harare viruses were detected in measles cases associated with the Quebec outbreak (Appendix), which was linked to a large B3-Harare outbreak in the USA (17). Three additional cases had genotype B3 viruses identified. While all three were sporadic, travel-related cases (South Africa, Ethiopia and Tunisia), the two cases with travel history to the African region had identical $\mathrm{N}-450$ sequences (matching the MVs/Kansas.USA/1.12, GenBank JX315576 named strain) (Figure 3). However these measles viruses were distinguishable by $\mathrm{H}$ gene sequencing (data not shown).

All genotype D4 viruses identified ( $n=17)$ had identical N-450 sequences (Figure 3 ), which were not identical to any named strain. All were associated with an outbreak in Ontario of unknown origin and for which epidemiological links could not be established between many of the cases (Appendix). Extended sequencing, including the $\mathrm{H}$ gene and the MF-NCR

Figure 2: Distribution of measles genotypes detected in $2015(n=56)$ by week of rash onset ${ }^{1}$

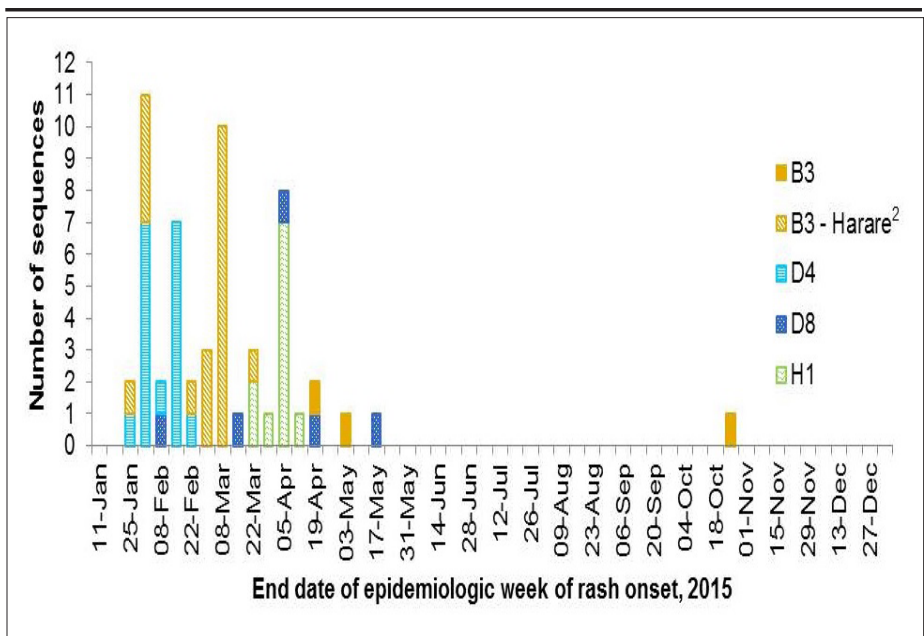

Epidemiological weeks are assigned in accordance with WHO guidelines (9) with week one beginning on the first Monday of the year.

'Genotype B3 sequences identical to sequence variant MVi/Harare.ZWE/38.09 GenBank accession number JF973033). (the non-coding region between the matrix and fusion genes) was performed to better characterize this outbreak. A detailed description is forthcoming.

Genotype $\mathrm{H} 1$ viruses were identified in 11 measles cases, all of which had either travel history to China, where genotype $\mathrm{H} 1$ is endemic (11) or were linked to cases with travel to China (Appendix). Nine of the viruses were identical to the MVs/Hong Kong.CHN/49.12 named strain (GenBank KC417295) while the remaining two viruses differed by a single nucleotide but were identical to each other (Figure 3).

The remaining measles cases that were genotyped were all identified to be genotype D8 $(n=5)$, four of which did not match any named strains (Figure 3). Two had identical $\mathrm{N}-450$ sequences and were both from the same outbreak associated with travel to India (Appendix). The remaining three cases with genotype D8 viruses were sporadic cases and all had unique $\mathrm{N}-450$ sequences. Two cases had a history of travel, to either India, where genotype D8 is endemic (11) or neighbouring Pakistan, while the third case was of unknown source. Globally, measles genotype D8 was the second most frequently reported genotype in 2015, based on submissions to the WHO measles nucleotide surveillance database (MeaNS) (18).

\section{Figure 3: Phylogenetic tree of measles $\mathrm{N}-450$ sequences detected in Canada in $2015(n=56)$}

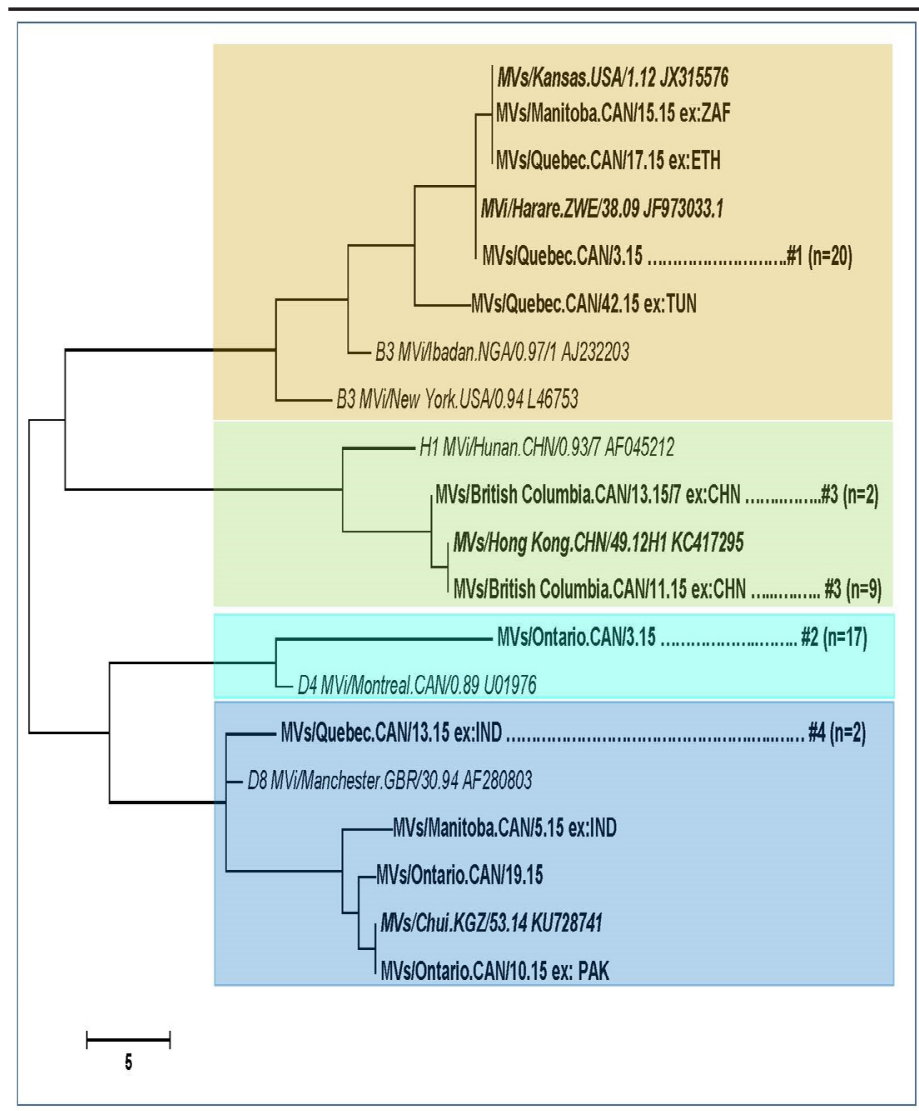

NOTE: Relevant WHO reference sequences (9) are shown in bold, italic font. Named strains, assigned in the WHO measles sequence database (MeaNS) (9), matching any Canadian sequences are shown in italics. Canadian sequences are shown in regular font and are identified by their WHO name which indicates province and week of rash onset. Cases with travel history are identified with "ex: $<3$ letter country code $>$." Outbreaks are represented by a single sequence and are tagged with their outbreak number (Appendix). The number of identical sequences identified in the outbreak is provided in brackets. The remaining sequences (without an outbreak number listed) are from sporadic cases $(n=6)$. The scale bar indicates number of nucleotide differences between branches. 


\section{Canadian measles in the global context}

Importations accounted for $4.6 \%(n=9)$ of cases in 2015. All imported cases were either adults (aged between

16 and 42 years) who were incompletely immunized for age $(n=7)$, or children too young to be immunized according to the routine schedule $(n=2)$. However, as giving measles-containing vaccine can be considered as early as six months of age when travelling outside of North America (16), these two children also represent missed opportunities for immunization.

Imported cases were exposed to measles during travel to most of the WHO regions: South-East Asian $(n=2)$, Western Pacific $(n=2)$, Eastern Mediterranean $(n=2)$, African $(n=2)$ and the Americas $(n=1)$. No importations were reported from the European region. Two importations each were reported from both China and India. One importation per country was reported from Ethiopia, Pakistan, South Africa, Tunisia and the United States.

A total of four outbreaks were reported in 2015, involving 190 cases. The source of exposure for the index case was identified for three of four outbreaks, involving travel to the United States, China and India. The largest outbreak resulted from a single importation from the United States, totalling 159 cases (Appendix). Although the number of cases reported for each outbreak ranged from two to 159 (median: 15), outbreak duration was generally short, with a median of three generations (range: 2 to 6). Genotypes B3, D4, H1 and D8 ( $n=1$, each) were identified. A source of exposure was not identified for 14 cases in 2015, all of which were reported by Ontario. Ten of these cases were described in detail elsewhere (19). Only one of these cases resulted in secondary spread (Appendix).

\section{Maintenance of measles elimination}

There are four criteria and indicators set out by PAHO, for the ongoing verification of measles elimination (Table 4). Canada met or partially met three of four indicators.

\section{Discussion}

There were 196 confirmed cases of measles reported in Canada in 2015 originating from all WHO regions except the European Region. The majority of these cases arose from a single importation associated with a popular tourist destination in the United States (17). This is the third highest total since elimination was achieved in 1998, following $2011(n=725)$ and 2014 ( $n=418)$. Similar to 2014, most cases $(81.1 \%, n=159)$ were in a non-immunizing religious community. Burden was highest among children, especially those aged five to 19 years, but also those aged five years or less. Most hospitalized cases were unimmunized. At least one case from every measles event (i.e., four outbreaks and six sporadic cases) was genotyped, with four genotypes were reported in 2015-B3, D4, H1 and D8. Every measles event was separate, as they all had a viral strain distinct from the others. After each event concluded, none of those viral strains were observed again in 2015 . The presence of cases with unknown source suggests that not all cases of measles have been reported, however these were relatively few. All outbreaks were well contained given the median outbreak duration was three generations.
Table 4: Pan American Health Organization essential criteria for the verification of measles elimination

\begin{tabular}{|c|c|c|}
\hline Criterion & Indicator & Description \\
\hline $\begin{array}{l}\text { Verify the } \\
\text { interruption of } \\
\text { endemic measles } \\
\text { cases for a } \\
\text { period of at least } \\
\text { three years from } \\
\text { the last known } \\
\text { endemic case, } \\
\text { in the presence } \\
\text { of high-quality } \\
\text { surveillance. }\end{array}$ & $\begin{array}{l}\text { Zero cases } \\
\text { of endemic } \\
\text { transmission. }\end{array}$ & $\begin{array}{l}\text { Criterion met. } \\
\text { Canada achieved measles } \\
\text { elimination status in } 1998 . \\
\text { Since then, molecular } \\
\text { and epidemiological data } \\
\text { continue to demonstrate that } \\
\text { no viral strain has circulated } \\
\text { for a period of one year or } \\
\text { more in Canada }(6,20,21,22) \text {. }\end{array}$ \\
\hline $\begin{array}{l}\text { Maintain } \\
\text { high-quality } \\
\text { surveillance } \\
\text { sensitive enough } \\
\text { to detect } \\
\text { imported and } \\
\text { import-related } \\
\text { cases. }\end{array}$ & $\begin{array}{l}>2 \text { suspect cases } \\
\text { per } 100,000 \\
\text { population } \\
\text { adequately } \\
\text { investigated. }\end{array}$ & $\begin{array}{l}\text { Criterion partially met. } \\
\text { As only confirmed cases } \\
\text { of measles are nationally } \\
\text { notifiable in Canada, this } \\
\text { indicator cannot be directly } \\
\text { assessed. } \\
\text { However, using data } \\
\text { obtained by the Measles and } \\
\text { Rubella Surveillance (MARS) } \\
\text { pilot project, the national } \\
\text { rate of measles-like illness } \\
\text { investigation was estimated } \\
\text { to be between } 12 \text { per } \\
100,000 \text { population (2006, } \\
\text { non-outbreak year) and } 19 \\
\text { per } 100,000 \text { population } \\
\text { (2011, outbreak year) (23). }\end{array}$ \\
\hline $\begin{array}{l}\text { Verify the absence } \\
\text { of endemic } \\
\text { measles virus } \\
\text { strains through } \\
\text { viral surveillance. }\end{array}$ & $\begin{array}{l}\text { Measles genotype } \\
\text { assessed in } 80 \% \\
\text { of outbreaks. }\end{array}$ & $\begin{array}{l}\text { Criterion met. } \\
\text { Genotype information } \\
\text { was available for } 100 \% \text { of } \\
\text { outbreaks reported in } 2015 \text {. }\end{array}$ \\
\hline $\begin{array}{l}\text { Verify adequate } \\
\text { immunization in } \\
\text { the population. }\end{array}$ & $\begin{array}{l}95 \% \text { of population } \\
\text { cohorts aged } \\
1 \text { to } 40 \text { years } \\
\text { have received } \\
\text { a measles- } \\
\text { containing } \\
\text { vaccine. }\end{array}$ & $\begin{array}{l}\text { Criterion not met. } \\
\text { As a national immunization } \\
\text { registry does not currently } \\
\text { exist in Canada, this criterion } \\
\text { cannot be directly assessed. } \\
\text { However, the } 2013 \text { Childhood } \\
\text { National Immunization } \\
\text { Coverage survey estimated } \\
\text { first dose measles-containing } \\
\text { vaccine coverage among } \\
\text { two year olds to be } 89.6 \% \\
\text { and second dose measles- } \\
\text { containing vaccine coverage } \\
\text { among seven year olds } \\
\text { to be } 85.5 \% \text { (24). This } \\
\text { estimate reflects a change in } \\
\text { methodology, as opposed to } \\
\text { a decline in coverage, from } \\
\text { previous years (e.g., } 95.2 \% \\
\text { and } 94.9 \%, 2011 \text { [25]). } \\
\text { Note that these are } \\
\text { average values; coverage is } \\
\text { heterogeneous and will be } \\
\text { higher in some areas and } \\
\text { lower in others. }\end{array}$ \\
\hline
\end{tabular}


For three of four criteria, Canada continues to meet or partially meet PAHO essential indicators for maintenance of measles elimination. One criterion previously met was not met in 2015: coverage with measles-containing vaccine. This likely reflects a change in methodology for estimating coverage, as opposed to a decrease in actual coverage. Notably, the 2016 federal budget announced $\$ 25$ million over five years in new investments that will support improving immunization coverage in Canada (26).

Globally, measles elimination and eradication continues to be a public health priority, with all WHO regions striving to achieve elimination goals. Three targets for measles eradication were also endorsed at the World Health Assembly in 2010, aimed at increasing immunization coverage with measles-containing vaccine and reducing in morbidity and mortality worldwide by 2015 (27). Nevertheless there is still room for improvement, as both the global targets and the elimination goals were not achieved by 2015 (28).

\section{Limitations}

There are a number of limitations to these data that merit consideration. The indicators of a well-performing surveillance system established by PAHO are based on investigation of measles-like illness (i.e., suspected cases), whereas only confirmed cases are nationally notifiable in Canada. As such, these data can only indirectly address the PAHO criteria. In addition, information on mortality and detailed information on morbidity (e.g., length of hospitalization, sequelae) are not currently captured by CMRSS or MARS, limiting the ability to completely describe the burden of illness due to measles in Canada. Finally, as immunization status is a derived variable that is affected by differences in schedule across jurisdictions, it may be discriminating between individuals on a factor that does not completely describe their risk of being infected with measles.

\section{Conclusion}

Both in Canada and abroad, maintaining high immunization coverage with measles-containing vaccine remains a significant public health effort, as well as an essential component of a strategy for achieving and maintaining measles elimination. Although importations and areas of low immunization coverage continue to challenge Canada's elimination status, surveillance data provided strong evidence that measles elimination has been maintained.

\section{Acknowledgements}

The authors gratefully acknowledge the continued cooperation and efforts of provincial and territorial surveillance and laboratory partners for providing and validating data captured by CMRSS and MARS, for referring specimens for molecular surveillance (genotyping) and for their review of the report content.

The authors are also grateful to Dr. Alberto Severini, Jennifer Beirnes and Lisa Podhorodecki and NML staff in the Genomics Core Services for their contribution in generating the molecular data.

\section{Conflict of interest}

No conflict of interest to declare.

\section{Funding}

This work was supported by the Public Health Agency of Canada.

\section{Appendix: Summary of measles outbreaks in Canada, ordered by earliest date of rash onset, 2015}

\begin{tabular}{|c|c|c|c|c|c|}
\hline No. & $\begin{array}{l}\text { Province/ } \\
\text { Territory }\end{array}$ & $n$ & $\begin{array}{c}\text { Days } \\
\text { (Generations) }\end{array}$ & Genotype & Description \\
\hline 1 & OC & 159 & $\begin{array}{l}72 \\
\text { (6) }\end{array}$ & B3- Harare ${ }^{1}$ & $\begin{array}{l}\text { The index case in this outbreak was exposed to measles during travel to a popular theme park in Califor- } \\
\text { nia, USA. } \\
\text { Subsequent spread occurred in the non-immunizing religious community to which the index case be- } \\
\text { longed. } \\
\text { Very few cases were reported outside of the religious community. }\end{array}$ \\
\hline 2 & ON & 18 & $\begin{array}{l}23 \\
\text { (3) }\end{array}$ & D4 & $\begin{array}{l}\text { The primary case in this outbreak was not identified. } \\
\text { Thirteen initial cases across four health units were identified. These cases had no epidemiologic link to } \\
\text { each other, or to a known case. However, based on dates of rash onset and genotype results, it is pre- } \\
\text { sumed that they shared a common source of exposure. } \\
\text { Only one of the cases resulted in secondary spread (to five household contacts). }\end{array}$ \\
\hline 3 & $B C$ & 11 & $\begin{array}{l}19 \\
\text { (2) }\end{array}$ & $\mathrm{H} 1$ & $\begin{array}{l}\text { Two cases of measles were reported among Canadians who were exposed during travel to China. These } \\
\text { cases were communicable during the return flight to Canada. } \\
\text { One measles case exposed during the flight was a visitor to BC and is not included in BC's provincial } \\
\text { case count. } \\
\text { Subsequent spread occurred among other passengers on the flight, or individuals who were epidemio- } \\
\text { logically linked to the flight. }\end{array}$ \\
\hline 4 & QC & 2 & $\begin{array}{l}14 \\
(2)\end{array}$ & D8 & $\begin{array}{l}\text { The index case had a history of travel to India. } \\
\text { One secondary case was reported, who was exposed to measles in a health-care setting. }\end{array}$ \\
\hline
\end{tabular}




\section{SURVEILLANCE}

\section{References}

1. World Health Organization (WHO). Measles fact sheet N286. Geneva: WHO; November 2015 [updated 2016 Mar]. http// www.who.int/mediacentre/factsheets/fs286/en/http://www. who.int/mediacentre/factsheets/fs286/en/.

2. World Health Organization (WHO). Monitoring progress towards measles elimination. Wkly Epidemiol Rec 2010;85(49):490-494.

3. National Advisory Committee on Immunization (NACl). Statement on elimination of indigenous measles in Canada. Can Dis Wkly Rep 1980;6:33-4.

4. Laboratory Centers for Disease Control (LCDC). Consensus Conference on Measles. Can Comm Dis Rep 1993;19(10);729.

5. Pan American Health Organization (PAHO). The XXIV Pan American Sanitary Conference. Expanded program on immunization - Resolution CSP24.R16. (1994).

6. King A, Varughese P, De Serres G, Tipples GA, Waters J, Working Group on Measles Elimination. Measles elimination in Canada. J Infect Dis 2004 May;189-Suppl 1:S236-42.

7. Public Health Agency of Canada. Case definitions for diseases under national surveillance. Can Comm Dis Rep 2009;35-Suppl 2:71-2.

8. World Health Organization (WHO). Standardization of the nomenclature for describing the genetic characteristics of wild-type measles viruses. Wkly Epidemiol Rec 1998;73:265.

9. Mulders M, Rota P, Brown K, Goodson J. Genetic diversity of wild-type measles viruses and the global measles nucleotide surveillance database (MeaNS). Wkly Epidemiol Rec 2015;90(30):373

10. Tamura K, Peterson D, Peterson N, Stecher G, Nei M, Kumar $\mathrm{S}$. Molecular evolutionary genetics analysis using maximum likelihood, evolutionary distance, and maximum parsimony methods. Mol Biol Evol 2011;28:2731.

11. Rota PA, Brown K, Mankertz A, et al. Global distribution of measles genotypes and measles molecular epidemiology. J Infect Dis 2011;204-Suppl 1:8514.

12. SAS Enterprise Guide 5.1. 2013;5.1.

13. Pan American Health Organization (PAHO). Plan of action. Documentation and verification of measles, rubella and congenital rubella syndrome elimination in the region of the Americas. Technical Document. 2010.

14. Government of Canada. Canada's provincial and territorial routine (and catch-up) vaccination programs for infants and children. Ottawa: PHAC; 2016 [updated 2016 Mar 2]. http//healthycanadians.gc.ca/healthy-living-vie-saine/ immunization-immunisation/schedule-calendrier/infantschildren-vaccination-enfants-nourissons-eng.php.

15. McLean HQ, Fiebelkorn AP, Temte JL, Wallace GS. Prevention of measles, rubella, congenital rubella syndrome, and mumps, 2013: Summary recommendations of the Advisory Committee on Immunization Practices (ACIP). MMWR 2013;62(RR04):1-34.
16. National Advisory Committee on Immunization (NACl). Canadian Immunization Guide. Part 4: Active vaccines measles vaccine. Ottawa: PHAC; 2015 [updated 2015 Apr 21]. http://www.phac-aspc.gc.ca/publicat/cig-gci/p04-measroug-eng.php.

17. Zipprich J, Winter K, Hacker J, Xia D, Watt J, Harriman K. Measles outbreak: California, December 2014-February 2015. MMWR 2015;64(06):153-4

18. World Health Organization (WHO). Measles surveillance data. Geneva; WHO; 2016 [updated 2016 May 18]. http:// www.who.int/immunization/monitoring_surveillance/burden/ $\mathrm{vpd} /$ surveillance_type/active/measles_monthlydata/en/ index1.html.

19. Gournis E, Shane A, Shane E, Arthur A, Berger L. Exploring gaps in surveillance of a small measles outbreak in Toronto. Can Comm Dis Rep 2016;42:146-8.

20. Public Health Agency of Canada. Elimination of measles, rubella and congenital rubella syndrome in Canada: Documentation and verification report. Ottawa: PHAC; 2011.

21. Shane A, Hiebert J, Sherrard L, Deehan H. Measles surveillance in Canada: Trends for 2013. Can Comm Dis Rep 2014;40:219-32.

22. Sherrard L, Hiebert J, Squires S. Measles surveillance in Canada: Trends for 2014. Can Comm Dis Rep 2015;41:15768.

23. T. EisBrenner. The MARS Pilot Project: Implementing realtime measles and rubella surveillance during elimination phase in Canada [dissertation]. Winnipeg MB: University of Manitoba; 2014.

24. Public Health Agency of Canada. Vaccine coverage in Canadian children: Highlights from the 2013 childhood National Immunization Coverage Survey (cNICS) [updated 2015 Jul 21]. Ottawa: PHAC; 2015. http://healthycanadians. gc.ca/publications/healthy-living-vie-saine/immunizationcoverage-children-2013-couverture-vaccinale-enfants/indexeng.php.

25. Public Health Agency of Canada. Vaccine coverage in Canadian children: Results from the 2011 Childhood National Immunization Coverage Survey. Ottawa: PHAC; 2015.

26. Government of Canada. Budget 2016: Growing the middle class. Chapter 5 - An inclusive and fair Canada. Ottawa: Queen's Printer; 2016. p. 181.

27. Sixty-third World Health Assembly May 2010, A63/18, Geneva, Switzerland: World Health Organization; 25 March 2010.

28. WHO Strategic Advisory Group of Experts (SAGE) on Immunization. 2015 Assessment report of the Global Vaccine Action Plan [updated 2016]. http://www.who.int/ immunization/global_vaccine_action_plan/en/. 